\title{
Subsistence Farming: Antidote to Famine and Food Insecurity
}

\author{
Olawuyi Oluseye M. ${ }^{1}$, Olawuyi Oluwasanjo J. ${ }^{2}$ \\ ${ }^{1}$ College of Basic and Applied Sciences, Rhema University, Aba \\ ${ }^{2}$ Department of Computer Science, \\ School of Science and Industrial Technology (SSIT) \\ Abia State Polytechnic, Aba. Nigeria \\ olawuyijo@yahoo.co.uk \\ $08059088508 \& 08055155511$
}

Accepted 05 April, 2012

\begin{abstract}
A famine is a widespread scarcity of food that may apply to any faunal species. This phenomenon is usually accompanied or followed by regional malnutrition, starvation, epidemic, and increased mortality. Emergency measures in relieving famine primarily include providing deficient micronutrients, such as vitamins and minerals, through fortified sachet powders or directly through food supplements. Aid groups have begun to use a famine relief model based on giving cash or cash vouchers to the hungry to pay local farmers, rather than buying food from donor countries as the latter distorts local food markets. Long-term measures include investment in modern agriculture techniques, such as fertilizers and irrigation, which largely eradicated hunger in the developed world. Minerals (largely petroleum) accounted for an increasing proportion of exports through the 1970s, increasing from 13 percent in 1955 to 35 percent in 1965, to 93 percent in 1975, and then to the peak 96 percent in 1985. The dependence on oil and a few other export commodities made Nigeria (being a consumer nation) particularly vulnerable to world price fluctuations.

God blessed Nigeria with vast arid land that can accommodate all classes of plants, crops, shrubs, and roots which should be able to feed the mass populace and should still remain in the form of exports which can generate foreign exchange earnings; hence to reverse our balance of payment deficit. Nigeria has emerging, though currently underperforming manufacturing sector is the second-largest on the continent, producing a large proportion of goods and services for the West African region.
\end{abstract}

Keywords: epidemic, poverty, hunger, food availability decline (FAD), global warming

\section{Introduction}

Agriculture has always been the basis and take-off point for socio-economic and technological advancement. This can be traced as far back as the neolithic revolution in 8000 B.C through to the industrial revolution of the $18^{\text {th }}$ and $19^{\text {th }}$ centuries and even up to the Chinese revolution of the $20^{\text {th }}$ century. Food surpluses have been plowed into all kinds of accumulation for development in any civilization. The motive which led to the "discovery" of the Americas was mainly to achieve food security in Europe by establishing new food supply routes. Although the explorers unexpectedly found precious minerals like gold and silver which they found more important and contributed to Europe's money supply, the new food preservation methods, spices and crops like corn, tomatoes, and beans which were taken back to Europe contributed significantly to the agriculture revolution which preceded the European industrial revolution.
In any country, the long-term goal to achieve sustainable development must be tied to a strong agricultural base. The rationale for others to "feed the world" fails to recognize this historical fact, at a time when developing countries are striving to emerge from poverty and debt. Without food security there is no way they can achieve a strong technological and industrial base. Investing in food crops means satisfying the primary needs of individuals: that is, food, shelter, clothing, as well as the pre-conditions for development. It may be acceded that the right of nations with the ability to produce their own food is a fundamental human right.

The rationale pursued by grain exporters to ship surplus food to other food deficit countries will not guarantee food security but rather aggravate the global socio-economic and environmental problems both in producing and recipient countries.

Developing countries, which due to very unfavourable conditions cannot produce enough food, are threatened with currency devaluation, higher tariffs associated with exports to get the needed foreign exchange and higher interest rates which are all backdrops of trade rules and Bretton Wood's agreements. They inevitably have to commit themselves to the payment of higher import bills with all or a greater percentage of the foreign exchange accrued from exports to achieve food self-sufficiency. Although trade plays an important role for such countries, the existing rules help predict that it should not be the starting point but a complementary support to the attainment of food security.

\section{Famine pandemic: causes, risks and effects}

A famine is a widespread scarcity of food that may apply to any faunal species. This phenomenon is usually accompanied or followed by regional malnutrition, starvation, epidemic, and increased mortality.

Food shortages in a population are caused either by a lack of food or by difficulties in food distribution; it may be worsened by natural climate fluctuations and by extreme political conditions related to oppressive government or warfare. One of the proportionally largest historical famines was that of the Great Famine in Ireland. It began in 1845 because of potato disease and occurred even as food was being shipped from Ireland to England. Only the English could afford to pay higher

How to Cite this Article: Olawuyi Oluseye M. , Olawuyi Oluwasanjo J.. "Subsistence Farming: Antidote to Famine and Food Insecurity" Science Journal of Agricultural Research \& Management, Volume 2012, Article ID sjarm-102, 7 Pages, 2012. doi: 10.7237/sjarm/102 
prices. Recently historians have revised their assessments about how much control the English could have exercised in reducing the famine, finding they did more to try to help than is generally understood. The conventional explanation until 1981 for the cause of famines was the Food availability decline (FAD) hypothesis. The assumption was that the central cause of all famines was a decline in food availability. However, FAD could not explain why only a certain section of the population such as the agricultural laborer was affected by famines while others were insulated from famines. Based on the studies of some recent famines, the decisive role of FAD has been questioned and it has been suggested that the causal mechanism for precipitating starvation includes many variables other than just decline of food availability. According to this view, famines are a result of entitlements, the theory being proposed is called the "failure of exchange entitlements" or FEE. A person may own various commodities which can be exchanged in a market economy for the other commodities he or she needs. The exchange can happen via trading or production or through a combination of the two. These entitlements are called trade-based or production-based entitlements. Per this proposed view, famines are precipitated due to a break down in the ability of the person to exchange his entitlements. An example of famines due to FEE is the inability of an agricultural labourer to exchange his primary entitlement, i.e., labor for rice when his employment became erratic or was completely eliminated.

Some elements make a particular region more vulnerable to famine. These include: $\left[{ }^{16}\right]$

- Poverty

- Inappropriate physical infrastructure

- Inappropriate social infrastructure

- A suppressive political regime

- A weak or under-prepared government

In certain cases, such as the Great Leap Forward in China (which produced the largest famine in absolute numbers), North Korea in the mid-1990s, or Zimbabwe in the early2000s, famine can occur as an unintentional result of government policy. Malawi ended its famine by subsidizing farmers against the strictures of the World Bank. During the 1973 Wollo Famine in Ethiopia, food was shipped out of Wollo to the capital city of Addis Ababa, where it could command higher prices. In the late-1970s and early-1980s, residents of the dictatorships of Ethiopia and Sudan suffered massive famines, but the democracies of Botswana and Zimbabwe avoided them, despite also have severe drops in national food production. In Somalia, famine occurred because of a failed state.

Many famines are caused by imbalance of food production compared to the large populations of countries whose population exceeds the regional carrying capacity. Historically, famines have occurred from agricultural problems such as drought, crop failure, or pestilence. Changing weather patterns, the ineffectiveness of medieval governments in dealing with crises, wars, and epidemic diseases such as the Black Death helped to cause hundreds of famines in Europe during the Middle Ages, including 95 in Britain and 75 in France. In France, the Hundred Years' War, crop failures and epidemics reduced the population by twothirds.

The failure of a harvest or change in conditions, such as drought, can create a situation whereby large numbers of people continue to live where the carrying capacity of the land has temporarily dropped radically. Famine is often associated with subsistence agriculture. The total absence of agriculture in an economically strong area does not cause famine; Arizona and other wealthy regions import the vast majority of their food, since such regions produce sufficient economic goods for trade.

Famines have also been caused by volcanism. The 1815 eruption of the Mount Tambora volcano in Indonesia caused crop failures and famines worldwide and caused the worst famine of the 19th century. The current consensus of the scientific community is that the aerosols and dust released into the upper atmosphere causes cooler temperatures by preventing the sun's energy from reaching the ground. The same mechanism is theorized to be caused by very large meteorite impacts to the extent of causing mass extinctions.

\section{Effect of climate change}

The signs of a new era in the world food economy are unmistakable. The old formula that was so spectacularly successful in expanding food production for nearly a halfcentury -- combining more and more fertilizer with higheryielding varieties -- no longer is working very well, and there is no new formula to take its place. Recent declines in food produced from oceanic fisheries and croplands give some sense of what the future holds.

The issue is not whether grain production can be expanded but whether it can be accomplished fast enough to keep up with the record growth in demand. There are many opportunities for increasing output, including substantial ones for productively using more fertilizer in countries such as India and Argentina. Nevertheless, restoring rapid, sustained growth in the grain harvest to the nearly three percent a year that prevailed from 1950 to 1990 will be difficult indeed.

Meanwhile, farmers face the uncertainties of climate change. If heat waves become progressively more intense, as climate models suggest, meeting future food needs could become even more difficult. Crop-withering heat waves of the sort experienced in 1995 in major food-producing regions -- such as the U.S. Corn Belt, the European Union. Ukraine, Russia, and Argentina -- could become routine. No one knows what the future will bring, but the rise in the Earth's temperature since 1979 suggests that the failure to check the increase in atmospheric levels of greenhouse gases could bring temperatures far higher than any since agriculture began.

On the demand side, the growth prospects are much more bullish. Not only is the world continuing to add nearly $90,000,000$ people a year, but the unprecedented rise in incomes in Asia, where more than half of humanity lives, is fueling a record growth in demand. Just satisfying the rise in world population requires 28,000,000 additional tons of grain per year, or 78,000 tons per day.

How to Cite this Article: Olawuyi Oluseye M. , Olawuyi Oluwasanjo J., "Subsistence Farming: Antidote to Famine and Food Insecurity" Science Journal of Agricultural Research \& 
As the growth in the oceanic fish catch halted and grain production slowed, the 1990s became the first decade in which both food sources were declining. The principal manifestations of this imbalance were the fall in world carryover stocks of grain and the return to use of idled cropland under commodity control programs.

During the first half of the decade, the production shortfall was offset by reducing stocks, but with carryover stocks in 1996 at 48 days of consumption -- little more than pipeline supplies -- the opportunity for further reductions is limited. Stock depletion may mark the transition from the old era of surpluses to the new one of scarcity. Future excesses of demand over supply can be eliminated only by rising prices, which is exactly what happened in late 1995 and 1996. The rise in grain prices that started in China in 1994 soon spread to the rest of the world, helping to double wheat and corn prices by the spring of 1996. Although these will decline somewhat in the immediate future, higher food prices are likely to become part of the economic landscape over the longer term.

The widening gap between the demand and the supply of grain can be seen in nearly all the more populous developing countries, In 1994, Worldwatch Institute projected the grain supply/demand balance to 2030 for 11 of the largest developing countries, home to about two-thirds of humanity. If their anticipated growth in population materializes by then, the need for imports everywhere except Brazil would increase far beyond the current level, even if there is no improvement in diets.

Worldwatch also submitted that Bangladesh, Brazil, Egypt, Ethiopia and Eritrea, Indonesia, Iran, Mexico, Nigeria, and Pakistan -- some of whose populations are projected to more than triple, would see their combined need for imported grain climb from 38,000,000 tons in 1990 to more than 400,000,000 tons in 2030.

\section{Global warming}

All these nations face a scarcity of cropland. Many, including the most populous countries -- China, India, and Indonesia -will lose this land as they industrialize. In some, future gains in food production will be constrained severely by water scarcity. Among them are Iran, Pakistan, and Mexico. For others, the sheer magnitude of projected population growth will overwhelm their agricultural systems. Nigeria, with a population that is projected to triple, is in this category.

Brazil is one of the countries with the largest potential for expanding production. Even with a hefty increase in grain output, though, it still will find itself scrambling to remain self-sufficient. Indeed, in recent years, Brazil has been losing the battle to be self-sufficient in grain, becoming the largest importer in the Western Hemisphere. Beyond this, it is projected to add nearly $100,000,000$ people by 2030 , reaching a total of $252,000,000$, roughly the same size as the U.S. today. Feeding another $100,000,000$ people while its population simultaneously moves up the food chain, consuming more livestock products, probably will take all the agricultural resources Brazil can mobilize.

\section{Risk of future famine}

The Guardian reports in 2007 that approximately $40 \%$ of the world's agricultural land is seriously degraded. If current trends of soil degradation continue in Africa, the continent might be able to feed just $25 \%$ of its population by 2025 , according to United Nations University - UNU's Ghana-based Institute for Natural Resources in Africa. As of late 2007, increased farming for use in biofuels, along with world oil prices at nearly $\$ 100$ a barrel, has pushed up the price of grain used to feed poultry and dairy cows and other cattle, causing higher prices of wheat (up 58\%), soybean (up 32\%), and maize (up 11\%) over the year. In 2007 Food riots have taken place in many countries across the world. An epidemic of stem rust, which is destructive to wheat and is caused by race Ug99, has in 2007 spread across Africa and into Asia.

Beginning in the 20th century, nitrogen fertilizers, new pesticides, desert farming, and other agricultural technologies began to be used to increase food production, in part to combat famine. Between 1950 and 1984, as the Green Revolution influenced agriculture, world grain production increased by $250 \%$. Much of this gain is non-sustainable. Such agricultural technologies temporarily increased crop yields, but as early as 1995, there were signs that they may be contributing to the decline of arable land (e.g. persistence of pesticides leading to soil contamination and decline of area available for farming). Developed nations have shared these technologies with developing nations with a famine problem, but there are ethical limits to pushing such technologies on lesser developed countries. This is often attributed to an association of inorganic fertilizers and pesticides with a lack of sustainability.

David Pimentel, professor of ecology and agriculture at Cornell University, and Mario Giampietro, senior researcher at the National Research Institute on Food and Nutrition (INRAN), place in their study Food, Land, Population and the U.S. Economy the maximum U.S. population for a sustainable economy at 200 million. To achieve a sustainable economy and avert disaster, the United States must reduce its population by at least one-third, and world population will have to be reduced by two-thirds, says study. The authors of this study believe that the mentioned agricultural crisis will only begin to impact us after 2020, and will not become critical until 2050. The oncoming peaking of global oil production (and subsequent decline of production), along with the peak of North American natural gas production will very likely precipitate this agricultural crisis much sooner than expected. Geologist Dale Allen Pfeiffer claims that coming decades could see spiraling food prices without relief and massive starvation on a global level such as never experienced before. Water deficits, which are already spurring heavy grain imports in numerous smaller countries, may soon do the same in larger countries, such as China or India. The water tables are falling in scores of countries (including Northern China, the US, and India) due to widespread over-pumping using powerful diesel and electric pumps. Other countries affected include Pakistan, Iran, and Mexico. This will eventually lead to water scarcity and cutbacks in grain harvest. Even with the over-pumping of its aquifers, China has developed a grain deficit, 
contributing to the upward pressure on grain prices. Most of the three billion people projected to be added worldwide by mid-century will be born in countries already experiencing water shortages.

After China and India, there is a second tier of smaller countries with large water deficits - Algeria, Egypt, Iran, Mexico, and Pakistan. Four of these already import a large share of their grain. Only Pakistan remains marginally selfsufficient. But with a population expanding by 4 million a year, it will also soon turn to the world market for grain. According to a UN climate report, the Himalayan glaciers that are the principal dry-season water sources of Asia's biggest rivers Ganges, Indus, Brahmaputra, Yangtze, Mekong, Salween and Yellow - could disappear by 2035 as temperatures rise and human demand rises. It was later revealed that the source used by the UN climate report actually stated 2350, not 2035 . Approximately 2.4 billion people live in the drainage basin of the Himalayan rivers. India, China, Pakistan, Afghanistan, Bangladesh, Nepal and Myanmar could experience floods followed by severe droughts in coming decades. In India alone, the Ganges provides water for drinking and farming for more than 500 million people.

\section{Characteristics of famine}

Famine strikes Sub-Saharan African countries the hardest, but with exhaustion of food resources, over-drafting of groundwater, wars, internal struggles, and economic failure, famine continues to be a worldwide problem with hundreds of millions of people suffering. These famines cause widespread malnutrition and impoverishment; The famine in Ethiopia in the 1980s had an immense death toll, although Asian famines of the 20th century have also produced extensive death tolls. Modern African famines are characterized by widespread destitution and malnutrition, with heightened mortality confined to young children.

Relief technologies including immunization, improved public health infrastructure, general food rations and supplementary feeding for vulnerable children, has provided temporary mitigation to the mortality impacts of famines, while leaving their economic consequences unchanged, and not solving the underlying issue of too large a regional population relative to food production capability. Humanitarian crises may also arise from genocide campaigns, civil wars, refugee flows and episodes of extreme violence and state collapse, creating famine conditions among the affected populations.

Despite repeated stated intentions by the world's leaders to end hunger and famine, famine remains a chronic threat in much of Africa and Asia. In July 2005, the Famine Early Warning Systems Network labelled Niger with emergency status, as well as Chad, Ethiopia, South Sudan, Somalia and Zimbabwe. In January 2006, the United Nations Food and Agriculture Organization warned that 11 million people in Somalia, Kenya, Djibouti and Ethiopia were in danger of starvation due to the combination of severe drought and military conflicts. [2] In 2006, the most serious humanitarian crisis in Africa is in Sudan's region Darfur.

Some believed that the Green Revolution was an answer to famine in the 1970s and 1980s. The Green Revolution began in the 20th century with hybrid strains of high-yielding crops. Between 1950 and 1984, as the Green Revolution transformed agriculture around the globe, world grain production increased by $250 \%$. Some criticize the process, stating that these new high-yielding crops require more chemical fertilizers and pesticides, which can harm the environment. However, it was an option for developing nations suffering from famine. These high-yielding crops make it technically possible to feed more people. However, there are indications that regional food production has peaked in many world sectors, due to certain strategies associated with intensive agriculture such as groundwater over-drafting and overuse of pesticides and other agricultural chemicals.

Frances Moore Lappé, later co-founder of the Institute for Food and Development Policy (Food First) argued in Diet for a Small Planet (1971) that vegetarian diets can provide food for larger populations, with the same resources, compared to omnivorous diets.

Noting that modern famines are sometimes aggravated by misguided economic policies, political design to impoverish or marginalize certain populations, or acts of war, political economists have investigated the political conditions under which famine is prevented. Amartya Sen states that the liberal institutions that exist in India, including competitive elections and a free press, have played a major role in preventing famine in that country since independence. Alex de Waal has developed this theory to focus on the "political contract" between rulers and people that ensures famine prevention, noting the rarity of such political contracts in Africa, and the danger that international relief agencies will undermine such contracts through removing the locus of accountability for famines from national governments.

\section{Effects of famine}

The demographic impacts of famine are sharp. Mortality is concentrated among children and the elderly. A consistent demographic fact is that in all recorded famines, male mortality exceeds female, even in those populations (such as northern India and Pakistan) where there is a normal times male longevity advantage. Reasons for this may include greater female resilience under the pressure of malnutrition, and the fact that women are more skilled at gathering and processing wild foods and other fall-back famine foods.

Famine is also accompanied by lower fertility. Famines therefore leave the reproductive core of a population-adult women-lesser affected compared to other population categories, and post-famine periods are often characterized a "rebound" with increased births. Even though the theories of Thomas Malthus would predict that famines reduce the size of the population commensurate with available food resources, in fact even the most severe famines have rarely dented population growth for more than a few years. The mortality in China in 1958-61, Bengal in 1943, and Ethiopia in 1983-85 was all made up by a growing population over just a few years. Of greater long-term demographic impact is emigration: Ireland was chiefly depopulated after the $1840 \mathrm{~s}$ famines by waves of emigration. 


\section{Levels of food insecurity}

In modern times, local and political governments and nongovernmental organizations that deliver famine relief have limited resources with which to address the multiple situations of food insecurity that are occurring simultaneously. Various methods of categorizing the gradations of food security have thus been used in order to most efficiently allocate food relief. One of the earliest were the Indian Famine Codes devised by the British in the 1880s. The Codes listed three stages of food insecurity: near-scarcity, scarcity and famine, and were highly influential in the creation of subsequent famine warning or measurement systems. The early warning system developed to monitor the region inhabited by the Turkana people in northern Kenya also has three levels, but links each stage to a pre-planned response to mitigate the crisis and prevent its deterioration.

The experiences of famine relief organizations throughout the world over the 1980s and 1990s resulted in at least two major developments: the "livelihoods approach" and the increased use of nutrition indicators to determine the severity of a crisis. Individuals and groups in food stressful situations will attempt to cope by rationing consumption, finding alternative means to supplement income, etc. before taking desperate measures, such as selling off plots of agricultural land. When all means of self-support are exhausted, the affected population begins to migrate in search of food or fall victim to outright mass starvation. Famine may thus be viewed partially as a social phenomenon, involving markets, the price of food, and social support structures. A second lesson drawn was the increased use of rapid nutrition assessments, in particular of children, to give a quantitative measure of the famine's severity.

Since 2004, many of the most important organizations in famine relief, such as the World Food Programme and the U.S. Agency for International Development, have adopted a fivelevel scale measuring intensity and magnitude. The intensity scale uses both livelihoods' measures and measurements of mortality and child malnutrition to categorize a situation as food secure, food insecure, food crisis, famine, severe famine, and extreme famine. The number of deaths determines the magnitude designation, with under 1000 fatalities defining a "minor famine" and a "catastrophic famine" resulting in over $1,000,000$ deaths.

\section{Antidotes to Global Famine: Nigeria}

\section{Famine prevention}

The effort to bring modern agricultural techniques found in the West, such as nitrogen fertilizers and pesticides, to Asia, called the Green Revolution, resulted in decreases in malnutrition similar to those seen earlier in Western nations. This was possible because of existing infrastructure and institutions that are in short supply in Africa, such as a system of roads or public seed companies that made seeds available. Supporting farmers in areas of food insecurity, through such measures as free or subsidized fertilizers and seeds, increases food harvest and reduces food prices.
The World Bank and some rich nations press nations that depend on them for aid to cut back or eliminate subsidized agricultural inputs such as fertilizer, in the name of privatization even as the United States and Europe extensively subsidized their own farmers. Many, if not most, of the farmers are too poor to afford fertilizer at market prices. For example, in the case of Malawi, almost five million of its 13 million people used to need emergency food aid. However, after the government changed policy and subsidies for fertilizer and seed were introduced, farmers produced recordbreaking corn harvests in 2006 and 2007 as production leaped to 3.4 million in 2007 from 1.2 million in 2005. This lowered food prices and increased wages for farm workers. Malawi became a major food exporter, selling more corn to the World Food Program and the United Nations than any other country in Southern Africa. Proponents for helping the farmers include the economist Jeffrey Sachs, who has championed the idea that wealthy countries should invest in fertilizer and seed for Africa's farmers.

\section{Managing River basins and Lakes}

Brazil has mandated civil society participation in key areas of development, and Canadian and Brazilian university partners are working out what that means at the grassroots level When environmental studies professor Ellie Perkins looks out her York University office window in Toronto, she can glimpse Black Creek on its urban journey through culverts, lowincome areas and golf courses into the Number River and out into Lake Ontario. Black Creek is not only linking the university community with diverse river basin neighbourhoods, it is also proving pivotal to understanding the national challenge of managing water systems in Brazil, where flooding, pollution, volatile climate and competing interests are critical issues.

\begin{abstract}
"You can use the river as an organizing tool to bring people together," says Dr. Perkins, Canadian co-director of the "Sister Watersheds Project" between York University and the University of Sao Paulo in Brazil, a project funded by CIDA through the University Partnerships in Cooperation and Development (UPCD) program and designed to improve democratic involvement in Brazil's water management.

The Brazilian government passed a national water law in 1997 that provides for citizenship representation on integrated river basin management teams. It also launched its Zero Hunger program in 2001, legislating citizen involvement on local food security councils. In both initiatives, Brazil is taking groundbreaking steps to involve citizens in the decisionmaking process - and Canadian universities are actively involved in facilitating the move.
\end{abstract}

In another UPCD project involving the grassroots in Brazil, Cecilia Rocha, the Canadian co-director and an associate professor at Ryerson University's school of nutrition, says, "What we are seeing in Brazil is the creation of spaces where you can have meaningful input by civil society on policy. The question is: how can civil society play that role effectively 


\section{Famine relief}

Deficient Micronutrient can be provided through fortifying foods. Fortifying foods such as peanut butter sachets (see Plumpy'Nut) and Spirulina have revolutionized emergency feeding in humanitarian emergencies because they can be eaten directly from the packet, do not require refrigeration or mixing with scarce clean water, can be stored for years and, vitally, can be absorbed by extremely ill children. The United Nations World Food Conference of 1974 declared Spirulina as 'the best food for the future' and its ready harvest every 24 hours make it a potent tool to eradicate malnutrition. Additionally, supplements, such as Vitamin A capsules or Zinc tablets to cure diarrhea in children, are used.

There is a growing realization among aid groups that giving cash or cash vouchers instead of food is a cheaper, faster, and more efficient way to deliver help to the hungry, particularly in areas where food is available but unaffordable. The UN's World Food Program, the biggest non-governmental distributor of food, announced that it will begin distributing cash and vouchers instead of food in some areas, which Josette Sheeran, the WFP's executive director, described as a "revolution" in food aid. The aid agency Concern Worldwide is piloting an method through a mobile phone operator, Safaricom, which runs a money transfer program that allows cash to be sent from one part of the country to another.

However, for people in a drought living a long way from and with limited access to markets, delivering food may be the most appropriate way to help. Fred Cuny stated that "the chances of saving lives at the outset of a relief operation are greatly reduced when food is imported. By the time it arrives in the country and gets to people, many will have died." US Law, which requires buying food at home rather than where the hungry live, is inefficient because approximately half of what is spent goes for transport. Fred Cuny further pointed out "studies of every recent famine have shown that food was available in-country - though not always in the immediate food deficit area" and "even though by local standards the prices are too high for the poor to purchase it, it would usually be cheaper for a donor to buy the hoarded food at the inflated price than to import it from abroad."

Ethiopia has been pioneering a program that has now become part of the World Bank's prescribed recipe for coping with a food crisis and had been seen by aid organizations as a model of how to best help hungry nations. Through the country's main food assistance program, the Productive Safety Net Program, Ethiopia has been giving rural residents who are chronically short of food, a chance to work for food or cash. Foreign aid organizations like the World Food Program were then able to buy food locally from surplus areas to distribute in areas with a shortage of food.

\section{Famine in Africa}

Historians of African famine have documented repeated famines in Ethiopia. Possibly the worst episode occurred in 1888 and succeeding years, as the epizootic rinderpest, introduced into Eritrea by infected cattle, spread southwards reaching ultimately as far as South Africa. In Ethiopia it was estimated that as much as 90 percent of the national herd died, rendering rich farmers and herders destitute overnight. This coincided with drought associated with an el Nino oscillation, human epidemics of smallpox, and in several countries, intense war. The Ethiopian Great famine that afflicted Ethiopia from 1888 to 1892 cost it roughly one-third of its population. In Sudan the year 1888 is remembered as the worst famine in history, on account of these factors and also the exactions imposed by the Mahdist state. Colonial "pacification" efforts often caused severe famine, as for example with the repression of the Maji Maji revolt in Tanganyika in 1906. The introduction of cash crops such as cotton, and forcible measures to impel farmers to grow these crops, also impoverished the peasantry in many areas, such as northern Nigeria, contributing to greater vulnerability to famine when severe drought struck in 1913.

However, for the middle part of the 20th century, agriculturalists, economists and geographers did not consider Africa to be famine prone (they were much more concerned about Asia). There were notable counter-examples, such as the famine in Rwanda during World War II and the Malawi famine of 1949, but most famines were localized and brief food shortages. The specter of famine recurred only in the early 1970s, when Ethiopia and the West African Sahel suffered drought and famine. The Ethiopian famine of that time was closely linked to the crisis of feudalism in that country, and in due course helped to bring about the downfall of the Emperor Haile Selassie. The Sahelian famine was associated with the slowly growing crisis of pastoralism in Africa, which has seen livestock herding decline as a viable way of life over the last two generations.

Since then, African famines have become more frequent, more widespread and more severe. Many African countries are not self-sufficient in food production, relying on income from cash crops to import food. Agriculture in Africa is susceptible to climatic fluctuations, especially droughts which can reduce the amount of food produced locally. Other agricultural problems include soil infertility, land degradation and erosion, swarms of desert locusts, which can destroy whole crops, and livestock diseases. The Sahara reportedly spreads at a rate of up to 30 miles a year. The most serious famines have been caused by a combination of drought, misguided economic policies, and conflict. The 1983-85 famine in Ethiopia, for example, was the outcome of all these three factors, made worse by the Communist government's censorship of the emerging crisis. In Sudan at the same date, drought and economic crisis combined with denials of any food shortage by the then-government of President Gaafar Nimeiry, to create a crisis that killed perhaps 250,000 people-and helped bring about a popular uprising that overthrew Nimeiry.

Numerous factors make the food security situation in Africa tenuous, including political instability, armed conflict and civil war, corruption and mismanagement in handling food supplies, and trade policies that harm African agriculture. An example of a famine created by human rights abuses is the 1998 Sudan famine. AIDS is also having long-term economic effects on agriculture by reducing the available workforce, and is creating new vulnerabilities to famine by overburdening poor households. On the other hand, in the 
modern history of Africa on quite a few occasions famines acted as a major source of acute political instability. In Africa, if current trends of population growth and soil degradation continue, the continent might be able to feed just $25 \%$ of its population by 2025, according to UNU's Ghana-based Institute for Natural Resources in Africa.

Recent examples include Sahel drought of the 1970s, Ethiopia in 1973 and mid-1980s, Sudan in the late-1970s and again in 1990 and 1998. The 1980 famine in Karamoja, Uganda was, in terms of mortality rates, one of the worst in history. $21 \%$ of the population died, including $60 \%$ of the infants.

In October 1984, television reports around the world carried footage of starving Ethiopians whose plight was centered around a feeding station near the town of Korem. BBC newsreader Michael Buerk gave moving commentary of the tragedy on 23 October 1984, which he described as a "biblical famine". This prompted the Band Aid single, which was organised by Bob Geld of and featured more than 20 other pop stars. The Live Aid concerts in London and Philadelphia raised further funds for the cause. An estimated 900,000 people die within one year as a result of the famine, but the tens of millions of pounds raised by Band Aid and Live Aid are widely believed to have saved the lives of around 6,000,000 more Ethiopians who were in danger of death. Essentially if Band Aid and Live Aid had never happened the death toll of the Ethiopian famine could have been as high as 7,000,000 or nearly a quarter of the population at the time.

The 2005-06 Niger food crisis was a severe but localized food security crisis in the regions of northern Maradi, Tahoua, Tillabéri, and Zinder of Niger. It was caused by an early end to the 2004 rains, desert locust damage to some pasture lands, high food prices, and chronic poverty. In the affected area, 2.4 million of 3.6 million people are considered highly vulnerable to food insecurity. An international assessment stated that, of these, over 800,000 face extreme food insecurity and another 800,000 in moderately insecure food situations are in need of aid.

The 2010 Sahel famine hit millions in Niger and across West Africa face food shortages after erratic rains hit farming in countries in the Sahel region south of the Sahara desert, the European Commission's aid group said Thursday. The erratic rains in the 2009/2010 agricultural season have resulted in an enormous deficit in food production in these countries," he said of nations such as Niger, Chad, northern Burkina Faso and northern Nigeria. He said strong leadership would be required from the United Nations and the rest of the international community to mobilise aid. "If we work fast enough, early enough, it won't be a famine. If we don't there is a strong risk."

July 6 saw the Methodist Relief and Development Fund (MRDF) aid experts say that more than 1,500,000 Nigerians were at risk of famine due to a month long heat wave that was hovering over Niger, Mali, Mauritania and Morocco. A fund of about $£ 20,000$ was distributed to the crisis-hit countries of Niger, Mali, Burkina Faso and Mauritania.

\section{Initiatives to increase Food Security}

Against a backdrop of conventional interventions through the state or markets, alternative initiatives have been pioneered to address the problem of food security. An example is the "Community Area-Based Development Approach" to agricultural development ("CABDA"), an NGO programme with the objective of providing an alternative approach to increasing food security in Africa. CABDA proceeds through specific areas of intervention such as the introduction of drought-resistant crops and new methods of food production such as agro-forestry. Piloted in Ethiopia in the 1990s it has spread to Malawi, Uganda, Eritrea and Kenya. In an analysis of the programme by the Overseas Development Institute, CABDA's focus on individual and community capacity-building is highlighted. This enables farmers to influence and drive their own development through community-run institutions, bringing food security to their household and region.

\section{Conclusion}

With all its complexities, the globalization process, either under the WTO or World Bank and IMF structural adjustment programmes, driven by Northern corporate exporters and marketed everywhere in the name of Northern culture and capital, offers formidable changes to food security systems, environmental and social structures in the developing world. Governments argue they can do little but bow to market pressures and facilitate its mechanisms. The developed world actually needs to shift away from cheap export-led food policies for developing countries to encourage more local production for local use everywhere. This requires more people on local land, not forcing people out of production all over the world. The over-all goal should be to promote a strong domestic agriculture base, the stepping stone to sustainable development with regards to socio-economic, environmental and cultural parameters.

\section{Acknowledgements}

The authors are greatly grateful and indebted to our research partners and colleagues in Rhema University, School of Science and Industrial Technology (SSIT), UN, FAO, UNICEF, and other humanitarian organizations whose materials are used during preparation for this paper. We would also like to thank the Management of Rhema University, and Abia State Polytechnic, Aba for providing the platform and the right atmosphere for this work. This paper is based on a presentation

\section{References}

1. Food and Agricultural Organization (FA0)Statistical estimates, World cereals Trade, (1996)

2. "Closing the Gender gap in Development", in the states of the World, (1993), a Worldwatch Institute Report, Towards a Sustainable Society. 